\title{
El origen de los bienes territoriales municipales
}

\author{
por \\ MANUEL GONZALEZ DIEZ
}

La aparición de la Circular de la Jefatura Superior del Servicio Nacional de Inspección y Asesoramiento de las Corporaciones Locales, de 8 de octubre de 1959, relativa a bienes comunales, muy oportuna y precisa, depara ocasión propicia a querer adentrarse un poco en el arcano, pleno de atracción, de lo remoto de tales bienes; porque interesando mucho en el presente, se muestra nebuloso y desdibujado en el pasado lo concerniente a los mismos.

En esa pluralidad y muchedumbres de cosas (colmena, el Ayuntamiento, de proporciones pequeñas y actividad grande) que, como de incumbencia municipal, constituye el quehacer de las Corporaciones y absorbe su atención, y de modo más directo la de su funcionario más representativo, el Secretario, no siempre es posible ahondar en el "porqué" de las mismas, si bien casi siempre es de necesidad. En tropel se le viene encima, con pertinaz acoso, no dejándole más tiempo para dedicárselo aún a las más importantes que el mismo que en un combate dispone un jinete para defenderse y desembarazarse de los que contra él cargan. Así, el análisis, la reflexión y la investigación rara vez son posibles. Todo ha de ser rápido y fulminante, objeto de repentina improvisación y espontánea acción. Cosa que 
en el campo de batalla será, quizá, lo indicado, pero mucho dudamos haya de serlo igualmente en el administrativo.

Ello es causa de que haya aspectos de lo municipial, y aspectos muy importantes, que se pasa sobre ellos tiempo y tiempo como lo hacemos por una calle muy frecuentada, sin enterarnos de lo primero que debimos saber: cuál es su nombre.

Tal ocurre con el origen de ciertos bienes municipales, que figuran - si figuran- en el inventario de un modo lacónico y de ellos se oye decir a cada momento "ces del común", pero en eso quedan todos sus antecedentes. Lo cual es bien poco.

Acaso no haga falta mucho más. Si nadie se los discute al Ayuntamiento, desde luego... Y de discutírselos, en habiende a su favor la posesión inmemorial...

Firme baluarte, sin duda, es la figura posesoria tradicional, tras la que bien puede hacerse fuerte el Municipio, definitivamente configurada hoy por el artículo 1.959 del Código civil, que, al transcurso de treinta años, da lugar a la prescripción adquisitiva, y consagrada de muy antiguo, ya de modo especial en lo referente a los bienes municipales, de lo cual son testimonio aquellas previsoras disposiciones de los reyes D. Alonso en 1325 y 1329, D. Pedro en 1331 y D. Juan II en 1432:

"Mandamos, que los Concejos, ciudades, villas y lugares que tuvieren compradas o ganadas por tiempo algunas aldeas, o fortalezas, c términos, estando en posesión dello, no sean desapoderados dellos sin que sean llamadas y oidas, y librado el derecho de cada uno por fuero y derecho...)

Mas, seria osadía considerarlo inexpugnable bastión, tanto más peligrosa cuanto que empeñando la clara visión de sus puntos vulnerables, que los tiene, puede inducir al error de dárse. los por inexistentes, en grave detrimento de la eficaz defensa.

Pero, conste, no es acerca de la fortaleza posesoria sobre lo que queremos discurrir, ni mucho menos meternos en libros de caballería, de buscarle tres pies al gato del derecho de posesión, igual para todo hijo de vecino, con el caporal de los vecinos (Ayuntamiento) incluído. 
Quizá estos escarceos nada más sea pura y simple curiosidad. Pero sólo por eso juzgamos como muy útil y conveniente que al menos a los que andamos metidos en las lides municipales sería bueno estar en cuestión tan importante como son los bienes municipales lo bastante impuestos de cual haya sido el proceso de su advenimiento al Municipio. $Y$ así suplir, "grosso modon, la auténtica y adecuada constancia que de ello debiera haber en cada caso particular.

Sabido es que las formas de obtención son muchas. Pero escasas veces será debido a compra. A los Municipios se les da mal acrecentar su patrimonios, y apenas si conservarlos. Para averiguar la génesis de los mismos, forzoso será remontar en larga distancia el curso de la Historia. Recomponiendo trazos dispersos de la misma, en relación con lo que tratamos, es como llegará a configurarse la razón del todo.

Dejando en la vertiente de allá de la Reconquista, desdibujado en la infinita lejanía de más remotos tiempos, el Imperio Romano, progenitor, según se dice, del Municipio, hagamos el examen contemplando el panorama hispánico desde la parte de acá de la Reconquista, donde se inicia la etapa en que cabe decir que nace lo español. Español auténtico; ni sucedáneo, ni trasplantado, ni injertado, trátase de instituciones o lo que sea.

La emprende Pelayo - al modo español ya- en Asturias en el año 718, para darle cima los Reyes Católicos al completar la unidad nacional en 1492.

Esa etapa, que marca el surgir de la nacionalidad española, es igualmente señalada como el punto de reaparición de las Municipalidades, ahora en su versión española, mejor dicho al estilo español. Resultado inmediato de las circunstancias impuestas por la empeñada lucha para reconquistar el suelo patrio de la dominación musulmana, a medida que surgían los reinos en las regiones que se iban liberando de la morisma, se iban configurando las formas de los gobiernos locales, que se denominaron concejos, universidades, y de alguna otra manera más, pero que en definitiva era la organización municipai. 
Los reyes, entregados ellos a las tareas de las armas, dejaban a los Municipios la de, tras el fragor de las mismas, ir estableciendo la convivencia social, naturalmente subvertida al paso de la guerra.

En ese período no había una legislación nacional uniforme. No había leyes nacionales. Eran las leyes municipales, o fueros, los que impregnaban de pertinentes disposiciones la forma de regir la vida social.

Nacieron, pues, nuestras Municipalidades al calor de los fueros.

Apoyándose en el Fuero de León, dado en 1020 por Alfonso $\mathrm{V}$, al que se considera el primer documento legislativo de nuestra Historia en que se hace mención de los concejos municipales, y que efectivamente sus artículos XXXV, XLV y XLVII contienen amplias disposiciones con atribuciones y prerrogativas concernientes al concejo (concilium), dice Lista (1):

"Que como no haya ninguna época anterior a que pueda referirse con preferencia la creación de las Corporaciones municipales, tenemos derecho para inferir que son tan antiguas como la Monarquia».

Los fueros, en su mayoría - que no todos estaban, como suele decirse, cortados por el mismo patrón, y fueron diversos a la vez que numerosos como se verá por los que hemos de citar, considerados como los más notables-, eran de gran previsión y de una regulación legal amplia.

A tales documentos ha de acudirse en cuanto queramos adentrarnos algo en el pasado, para que alumbren los pasos que hayamos de dar. Así lo aconseja nada menos que la Real Academia de la Historia (2):

«El estudio de los fueros municipales y cartas de población es indispensable para el conocimiento de la historia legal, civil, administrativa y económica de los pueblos, para la historia de sus costum-

(1) Discurso sobre el régimen municipal de España. aRevista de Madrido, tomo 4, página 56 .

(2) Catálogo de la Colección de Fueros y Cortas Pueblas de España. 1852. Introducción. 
bres y de su vida intima, de que apenas dan noticia nuestros cronistas).

Al referirse a los fueros, Martínez Marina, quizá el mejor apologista español de los mismos, hace de ellos esta semblanza (3) :

«... cartas expedidas por los reyes o por los señores en virtud de su privilegio de soberanía, en que se contienen constituciones, ordenanzas, leyes civiles y criminales, ordenadas a establecer con solidez los comunes de villas y ciudades, erigirlas en municipalidades, acomodándolas a la constitución pública del reino y a las circunstancias de los pueblos).

El mismo, se extiende en definiciones acerca de tales piezas legislativas, cual ésta:

"Carta-puebla, escritura de población y pactos anejos a ella; contrato entre el nuevo dueño territorial, que concedia el suelo, posesiones y términos).

Por los fueros se hizo el señalamiento de los términos municipales (4), que llevaba implícito casi siempre lo que habia de ser tenido por bienes del común, o concejiles (5), y debían ser éstos todos cuantos no quedasen como realengos, abadengos, de señorío, o les fueran asignados expresamente en propiedad particular a los moradores. Así se desprende de lo que es traducible -difícil en los más antiguos al estar escritos, por lo gene-

(3) Ensayo histórico-critico sobre la legislación y principales cuerpos legales de los reinos de Lebn y Castilla, libro IV, núm. 1 y siguientes.

(4) Valencia tuvo su ley especial de términos (Los termens del Regne de Valencia), dada por Jaime $I$, en 1250, al decir de Danvila: aMemorias de la Real Academia de la Historian, t. XIV.

(5) Concepto único, según LISTA, en El colectivismo agrario, que tuvieron en principio los bienes municipales. Hasta que las leyes de Partida, dadas en el siglo xII por Alfonso $X$ el Sabio, establecieron la diferenciación con acuales son las cosas del común de cada cibdad o villa de que cada uno puede usar (ley 9.2) o de que non puede cada uno usar (ley 10.a) D. 
ral, en latín bárbaro- de varios documentos de esos (6), y que, en contexto y concordancia como auxilio a la función interpretativa, patentizan dos Privilegios de Canfranc llegados a nosotros traducidos, si bien un poco a la buena de Dios, y más aún el fuero, relativamente moderno ya, dado a las nuevas poblaciones asentadas en Sierra Morena, inspirado sin duda en los precedentes, pero que su buena redacción en castellano le hace perfectamente claro e inteligible.

Los primeros (7), así concebidos (son similares):

«Sepan todos que nos por la gracia de Dios rey de Aragón y Conde de Barcelona buscando el crecimiento y la mejora de nuestra villa de Campo Franco, damos, concedemos y laudamos a los hombres de esta villa presentes y futuros por siempre y a esa misma villa de Campo Franco por términos perpétuos asignamos aquellos puertos que se llaman... de manera que estos puertos con todo lo que en ellos hay y habrá lo tengan por sus propios términos perpétuamente la villa y los hombres de Campo Franco que alli hay y habrá siempre por los siglos todos. Queremos pues y mandamos firmemente que ningún hombre viviente ni mujer se atreva jamás a apacentar algún género de animales o tener algún adempribio en los dichos puertos, a no ser los habitantes del Campo Franco presentes y futuros solo y no otros cualquiera jamás sin o licencia y la voluntad de ellos...; ningún infanzón o cualquier otro se atreva a ponerles im. pedimento o estorbo o de algún modo despojarlos en algo en esos términos y los que esto hagan tendrán siempre nuestra ira y además por pena sin excusa ninguna pecharán mil sueldos».

El segundo (S), contiene, entre otros, estos preceptos:

(18. A cada poblador se le dará en lo que llaman navas o campos, cincuenta fanegas de tierra de labor por dotación y repartimiento suyo.

(6) Si nos lo permite la extensión consentida para este trabajo, al final, como adición, transcribimos partes entresacadas de ellos en cuanto tengan relación con lo que tratamos.

(7) Uno, por Alfonso II, en Jaca, agosto de 1170 . Otro, por Pedro II, en Monzón, 9 de abril de 1210.

(8) Dado por Carlos III, en Madrid, a 5 de julio de 1767 (Novísima Recopilacion, libro VII). 
9. ... y les quedará libertad en los valles y montes para aprovechar los pastos con sus vacas, ovejas, cabras y puercos, y lo mismo la leña para los usos necesarios.

11. Demarcados los terrenos que se asignen a cada pueblo, se pondrán señales, y después se reducirán a mojoneras de piedra, que dividan este término del de otros pueblos.

12. ... habiendo en cada pueblo un libro de reparíimiento, que contenga el número de las suertes o quiñones en que está dividido, y el poblador en que se repartieron; dándosele a cada uno de los vecinos copia de su hijuela o partida, para que le sirva de título en lo sucesivo.

21. Cada Concejo deberá tener una dehesa boyal (9) para la suelta y manutención de las yuntas de labor.

22. Si creyese conveniente establecer algunas tierras para una senara o peujar concejil, que laboreen los vecinos por concejadas en días libres, y cuyo producto se convierta en los gastos del común y otras obras públicas, también las podrá demarcar, anotándose en los libros de repartimientos igualmente que la dehesa boyal.

70. Los pobladores serán obligados a la construcción de iglesias, casas capitulares, cárceles, hornos y molinos como destinados a la utilidad común; y en lo sucesivo concurrirán a la reparación en falta de caudales comunes.

71. Los productos del horno y molino quedarán destinados para Propios del Concejon.

De análogo contenido al fuero y privilegios transcritos debe ser el documento fecha 4 de marzo de $\mathbf{1 7 4 1}$-cuya forma literal no hemos podido alcanzar-, por el cual hizo la Corona donacion a Albacete y Chinchilla de cuantas tierras baldías y realengas, eriales, montes, prados, egidos, agua y demás existentes en los términos de dichos Municipios, con facultad para cerrar y aco. tar los que estimaren convenientes...

«... a excepción de la parte de sierra, pues ésta queda para el aprovechamiento y utilidad común de los vecinos de uno y otro pueblo, abierta a fin de que se utilice la leña, carbón, pastos, aguas y demás que produzca su territorion.

(9) Fué Alfonso el Sabio el creador de ellas, concediendo una superficie de tres aranzadas por yugo de bueyes a los labradores pobres. 
Estaria falto de sentido descartar toda otra forma de adquisición, de las diversas que siempre fueron usuales desde la aparición del Derecho romano. El término municipal de Espiel es motivado a una compra de su Concejo al de Córdoba, formalizada en escritura de 2 de junio de 1641, por importe de 265.704 maravedises (10). A título oneroso fué también adquirido el de Villar del Buey (Zamora), del Real Patrimonio, por escritura de 17 de diciembre de 1740. Y el Estado tiene hechas a los $\mathbf{M u -}$ nicipios cesiones, muy importantes a veces, de las que son ejemplo :

- Al de Madrid, el parque del Retiro, por Decreto de 6 de noviembre de 1868.

- Al de Zamora, el Castillo, por Ley de 28 de junio de 1898.

- Al de Vigo, el monte Castro, por Ley de 16 de diciembre de 1908.

- Al de Pamplona, por Ley de 2 de agosto de 1888, una muy original: le cede los derribos de varios baluartes y algunos cuarteles a cambio de:

A) El soto de Anzoain ;

B) 750.000 pesetas en metálico, y

C) Dotar gratuitamente de agua a los cuarteles y dependencias militares durante veinticinco años.

El tiempo fué, sí, consolidando, hasta en algunos casos añadiendo $-\mathrm{y}$ en los más desgajando-, lo obtenido por fuero 0 privilegio, pero de tales elementos de concesión proviene, eso es incuestionable, la casi totalidad de la propiedad inmobiliaria municipal, sobre todo la rústica. Unas breves referencias bastarán a constatarlo. Así la Sentencia de 30 de noviembre de 1859. que puntualiza otras del Consejo de Castilla de 1671:

(10) Más o menos en potencia, la enajenación de términos y aun la de ejidos ha estado prohibida desde muy antiguo. Hay menciones a ello en las Partidas, y hacen referencia las leyes de la Novísima Recopilación del títula XXI, libro VII, y la sentencia de 25 de mayo de 1853. 
«... usando de su poderio real, absoluto como Rey y Señor natural, hizo merced, gracia y donación al Concejo, Justicia y Regimiento de la villa de... de las dichas 400 fanegas de tierra en sembradura en la Mojonera de Valsalobre y Muela de la Madera».

$\mathrm{Y}$ el artículo 14 de la Ley de 16 de agosto da 1841 , en que quedó definida la situación foral de Navarra:

«No se hará novedad alguna en el goce y disfrute de montes y pastos de Andía, Urbaza, Bardenas y otros con arreglo a las leyes de Navarra y privilegios de los pueblos).

Y la elocuente introducción del "Catálogo de !a Colección de Fueros y Cartas Pueblas», de la Real Academia d. la Historia :

"Cuando la legislación se hizo general, cuando el poder público intervino en la administración interior de nuestras villas y ciudades, cesó entonces el interés por los fueros municipales y cartas de población, a no haber en ellos designación de términos, concesión de pastos o varias franquicias cuya conservación les interesaba) (11).

Buscar en los archivós municipales ya se sabe que es obra de titanes, pero de proponérselo, dariase con verdaderas joyas de la enunciada índole, pues aun contando con la indolericia de lcs municipes de aquellos tiempos -que de algo le han venido a los de éstos- para el derecho llevar de las cosas del común, algo, empero, se haría en cumplimiento de aquellas disposiciones de los Reyes D. Fernando y D.* Isabel, dadas en 1500 y 1501 :

(1... que hagan (los Corregidores) arca donde estén los privilegios y escrituras del Concejo a buen recaudo ; ... y haga (el Escribano) que en la dicha arca estén las Siete Partidas, y las leyes de Fuero, y este nuestro Libro, y las más leyes pragmáticas...)

«Mandamos a los Escribanos de Concejo de todas las ciudades

(11) $\mathrm{Si}$ bien -decimos nosotros- ni aún interesándoles los conservaron los pueblos, cuya incuria al respecto ha sido tremenda. Hermosas Cartas pueblas hemos visto en determinado Municipio en estado lamentable: isirviendo de alfombra en el archivo! De otro Municipio sabemos que expurgaron su archivo ia paladas! 
y villas de nuestros Reynos...; y ansimismo, que hagan hacer otro libro de pergamino enquadernado, en que se escriban todos los privilegios que las dichas ciudades y villas y sus tierras tienen, y todas las sentencias que en su favor se han dado, asi sobre razón de los términos como sobre otras cualesquiera cosas tocantes al bien y procomún de las dichas ciudades y villas; en el cual ansimismo se escriban todos los privilegios que de aquí adelante les fueren dados $y$. otorgados, y las sentencias que en su favor fueren dadas...)

Joyas documentales esas que, aparte su extrínseca impor: tancia para la investigación principalmente, habrían de tener un valor positivo incalculable aún, pues no han perdido toda su. virtualidad :

«... en que el Ayuntamiento de $T$., aunque ha intentado probar haber ejercido actos administrativos sobre los terrenos objeto del deslinde, no quiere decir que no pertenecieran a $\mathrm{C}$., el cual ha presentado antiguas ejecutorias». (Sentencia de 27 de junio de 1906.)

Bueno es haber llegado, cabalgando sobre la posesión, a esa. meta en que por la soldadura prescriptiva queda vinculado el do. minio. Pero es el caso que asimismo otros galopan incesantemente por ganarle el "handicap" al Municipio, y cuando éste no la ejercita, la huéspeda se le muestra rezongona:

«... sólo tendria utilidad (la acción reivindicatoria) cuando el Ayuntamiento, demandante, presentase un título más fuerte y eficaz, pues al demandado le basta la posesión). (Sentencia de 30 de noviembre de 1889.)

«... la material tenencia de las láminas por el Ayuntamiento de B. constituye un verdadero estado posesorion. (Sentencia de 9 de julio de 1891.)

Mejor es siempre a la vez que estar asistidos con la notoriedad y la posesión, tener documentos o, al menos, referencias auténticas. Oros son triunfos. Díganlo varios Ayuntamientos que aferrándose a un mugriento pergamino, como a un clavo ardiendo, les ha ido bien en peliagudos pleitos. Batirse únicamente al amparo del escudo de la posesión, aunque sea inmemorial, aparte ser algo así como hacerto en ${ }^{-}$retirada, de escaso 
honor, es un peligro en potencia, como ahora se dice. Cobertura quebradiza es esa, cual frágil copa de cristal:

«... nada significan los autos alegados para justificar la posesión de hecho del Ayuntamiento de R., porque tales actos de jurisdicción o posesorios sólo son medios supletorios y subsidiarios de prueba». (Sentencia de 29 de mayo de 1899.)

Cuando no es arma de dos filos que se vuelve a veces contra el Municipio, alguacilándolo. Máxime ante tan diversa naturaleza que tienen los bienes municipales y siendo como son tan pródigos en circunstancias y situaciones complejas, propicio a que la posesión misma quede desdibujada, y al subrepticio deslizarse de sutiles fraguadores de la desintegración del patrimonio comunal:

"La posesión reconocida a un pueblo no puede interpretarse reconociéndole la mancomunidad de pastos...) (Sentencia de 10 de marzo de 1896.)

Se observa que en los inventarios los bienes municipales adolecen de una racional descripción, en cuanto a los territoriales, $y$, sobre todo, de referencias a su origen. Esto es bastante perturbador. Aunque generalmente se haya venido reconociendo y aceptando como de la pertenencia del Municipio "aquellos» bienes, porque se sabe tradicionalmente los ha venido poseyendo, ello no debe bastar, ni obstar, a reconstruir sus antece. dentes, su historial. Algo debe haber que hable de ellos, que de algún modo los mencione. Ese "algo" simplemente figurado en el libro Inventario es buena profilaxis porque, sin más, echa para atrás a osados pretendientes de lo que a sabiendas no es suyo. $\mathrm{Y}$ también dice de orden, interés, y sentido del administrar y de lo administrativo.

Hemos intentado dar el hilo. Véase donde sea posible por él sacar el ovillo. 


\section{Adición (REFERIda EN LA NOTA 6)}

De el fuero de Arguedas, dado en 1092 por Sancho Ramírez, rey de Aragón y Navarra:

«Et do a vos en toda la Bardena de Arguedas, en qoanta yo recibo hierbadgo, la caza y madera que tayllades a vuestros huerbos. Et leynna e carbón et yerbas a vuestros ganados. Et que podais escaliar (roturar) en la dicha Bardena ho a vos ploguiere en los yermos. Et do a vos, hombres de Arguedas, término entre vos et Vaitierra de aquel cabezo de entre ambos los vaylles de val de Estinyel ad aquella torr de trescales, é ad aquel poblo de sobre el soto del Yugo. Et do a vos la meatat de aquel soto de Congostina, a heredat; et en la otra meatat del soto que pazcan vuestros ganados, et fagades hyerba, et taylledes leynna seca, et tamariz.»)

De el de Logroño, dado en 1095 por Alfonso VI:

«Et istos términos habent istos populatores de Logronio per nomen de Santo Iuliano usque ad illa Ventosa, et de Veguera usque ad Maraignon, et usque in Leguarda, et dono vobis meos popu'atores de Logroño infra istos términos suprascristas terras, vineas, ortos, molendinos, cañares, et toto quantum potueritis inveniere, quae ad mean regiam personam pertinet, vel pertinere dobet, ut habeatis, et posideatis meum donativum firmiter abasque ulla ocasiones, vos, et filii vestri, et omnis generatio, vel posteritas vestra.»

De el de Calatayud, dado en $\mathbf{1 1 3 1}$ por Alfonso I el Batallador :

"In primis quod habeatis medianeto cum totas meas terras ad vestram portam de Calatayub. Et ego dono eis cum bona voluntate, villa quae dicitur Aranda cum suo término, ut habea illa libera, et firma per secula cuncta. Dono vobis términos ad homines de Calatayub. Dono vobis todas cum suo término, et quomo las acuas cadent usque Calatayub et quomodo vadit illa serra de Castella pro nómine Albediano et quomodo vadit ipsa serra de Midorna usque ad Calatayub. Et dono vobis Berdello cum suo término usque ad Calatayub. Et 
dono vobis Caravantes cum suo término usque ad Calatayub. Et dono vobis Albalat cum suo término, et inde usque ad Calatayub. Et dono vobis Tariza cum suo término, et inde usque ad Calatayub. ( $\mathrm{Y}$ sigue citando.)"

De el de Guadalajara, dado en 1133 por Alfonso VI:

"Otorgo y mando que la media parte de aquel montazgo sea guardado para mi y la otra media parte a huerbos de los varones de Guadalfayara, y a ellos sea dado y que fagan de ello a su voluntad. Estos son los términos de Guadalfayara los cuales otorgamos y a ellos damos Daganzo y Dagantiel, Anorcini, Ferezuela, Dascariche, Fontana, etc. (Sigue citando.))

De el de Castillo de Aurelia (hoy Colmenar de Oreja), dado en 1139 por Alfonso VII :

"Sobre todo aquesto otorgo tales términos que haya el Castillo de Aurelia conviene a saber: desde aquel lugar o cayere Jarama en Tajo hasta Fontigola, e dende fasta Armela, e dende fasta Ocaña la mayor, e dende fasta Noblejas, e dende fasta en las dos Noblejas, e dende fasta en Alfariella, e dende fasta dentro en las Alcarrias, así como descende Tajuña en Jarama.»

De el de Roa, dado en 1143 por igual rey:

"Dono etiam eis ipsam villam Roam, cum omnibus suis terminis, hermos et populatis, sicut sos abuise cognoscitur a temporibus mei avi regis Aldephonsi: dono quoque eis in hereditatem villam (cita varias villas, de análogo modo al de Calatayud). Praeterea dono eisdem populatoribus duas partes de illa valle de Ozate, cum omnibus causis, hermis, et populatis quae in eis duabus partibus sunt; praeterea dono eisdem populatoribus omnes montes, et pinares de meo realengo; mando et concedo eis ut laborent per totum meo realengo quoe ex una parte Dori, et ex altera hermun, et desertum ad Aslanza usque ad Serram (sigue citando otras sierras como límites).)

Dè el de Sahagún, dado en 125̃5:

(Et mandamos, que en la defensa del soto pascan los de S. Fagund, tambien los del Monasterio cuemo los del Conceio; et non 
la rompan los del Monasterio nin los del Conceio; et finque el sennorio del soto, del mont, et de los pastos, al abad; et norte hy el abad, o qui el mandare quando quisiere, et los del Coceio no. Et el Conceio aian pastos en los montes poro estan los moiones; et quanto fue rompido contra villa Pecenin, quier de parte del abad, quier de parte del Conceio desde el tiempo del rey D. Alfonso mio visabuelo acá, finquen por a pastos. Et los exidos, et las carreras, que se enderecen, et se entregun tambien de parte del Monasterio cumo de parte del Conceio. Ea los huertos téngalos el Monasterio cuemo los tiene, hy el Conceio los suyos cuemo los tiene.)

De los muchos fueros habidos, los calificados como más interesantes fueron:

Además de el de León, al que ya se hizo mención, extendido después a Carrión, Villavicencio y Llanes, el de Nájera, dado por Sancho el Mayor de Navarra y confirmado por Alfonso VI en 1076 ; el de Sepúlveda, por el mismo rey en igual año y confirmado por Fernando IV en 1309, extensivo más tarde a Roa, Uclés, Segura y Puebla de Don Fadrique; el de Logroño, por, Alfonso VI en 1095, extensivo a Castro Urdiales, Miranda de Ebro, Santo Domingo de la Calzada, Laredo, Peñacerrada y Haro; el de Sahagún, por igual rey en 1096, corregido por Al fonso VII en 1152, extensivo con modificaciones a Oviedo y Avilés; el de Alcalá de Henares, en 1114; el de Toledo, por Alfonso VII en 1118, extensivo a Córdoba, Murcia, Sevilla y Carmona, y con éste los de Salamanca y Escalona; el de Mo. lina, por igual rey en 1154; el de Palencia, por Alfonso VIII en 1181; el de Haro, por igual monarca en 1187 ; el de Cuenca, por el mismo monarca en 1190, extensivo a Plasencia, Consuegra, Baeza y Alarcón; el de Madrid, por igual monarca en 1202 ; los de San Sebastián, Benavente, Puebla de Sanabria y Cáceres, por Alfonso IX en 1229; Aguilar y Trujillo, por igual monarca; Segovia, por Sancho IV; Medina Sidonia, Gibraltar y Niebla, por Fernando IV; Alcalá la Real, por Alfonso XI ; Salinas-Mondragón y Cestona-Oropesa, por Juan $I$. 


\section{Obras CONSUltadas}

"Colección de Fueros municipales y Cartas-Pueblas», de Muñoz y Romero, Madrid, 1847.

"Catálogo de Fueros y Cartas-Pueblas de España), de la Real Academia de la Historia, Madrid, 1852.

Algunos Catálogos de Ayuntamientos e Inventarios de archivos municipales. 